\title{
Gastric Poorly Cohesive Carcinoma
}

National Cancer Institute

\section{Source}

National Cancer Institute. Gastric Poorly Cohesive Carcinoma. NCI Thesaurus. Code C95743.

An adenocarcinoma that arises from the gastric mucosa and is characterized by the presence of isolated malignant cells or malignant cells that form small aggregates. This category includes signet ring cell adenocarcinomas, adenocarcinomas that are composed of malignant cells resembling lymphocytes and histiocytes, and adenocarcinomas that are composed of malignant cells with deeply eosinophilic cytoplasm. 